\title{
Application of the UK Foresight Obesity Model in Ireland: The Health and Economic Consequences of Projected Obesity Trends in Ireland
}

\author{
Laura Keaver ${ }^{1}$, Laura Webber ${ }^{2}$, Anne Dee ${ }^{3}$, Frances Shiely ${ }^{1}$, Tim Marsh $^{2}$, Kevin Balanda ${ }^{4}$, Ivan Perry ${ }^{*}$ \\ 1 Department of Epidemiology and Public Health, University College Cork, Cork, Ireland, 2 UK Health Forum, London, United Kingdom, 3 Health Service \\ Executive Department of Public Health, Limerick, Ireland, 4 Institute of Public Health in Ireland, Dublin, Ireland
}

\begin{abstract}
Background: Given the scale of the current obesity epidemic and associated health consequences there has been increasing concern about the economic burden placed on society in terms of direct healthcare costs and indirect societal costs. In the Republic of Ireland these costs were estimated at $€ 1.13$ billion for 2009 . The total direct healthcare costs for six major obesity related conditions (coronary heart disease \& stroke, cancer, hypertension, type 2 diabetes and knee osteoarthritis) in the same year were estimated at $€ 2.55$ billion. The aim of this research is to project disease burden and direct healthcare costs for these conditions in Ireland to 2030 using the established model developed by the Health Forum (UK) for the Foresight: Tackling Obesities project.

Methodology: Routine data sources were used to derive incidence, prevalence, mortality and survival for six conditions as inputs for the model. The model utilises a two stage modelling process to predict future BMI rates, disease prevalence and costs. Stage 1 employs a non-linear multivariate regression model to project BMI trends; stage 2 employs a microsimulation approach to produce longitudinal projections and test the impact of interventions upon future incidence of obesity-related disease.

Results: Overweight and obesity are projected to reach levels of $89 \%$ and $85 \%$ in males and females respectively by 2030. This will result in an increase in the obesity related prevalence of CHD \& stroke by $97 \%$, cancers by $61 \%$ and type 2 diabetes by $21 \%$. The direct healthcare costs associated with these increases will amount to $€ 5.4$ billion by 2030. A $5 \%$ reduction in population BMI levels by 2030 is projected to result in $€ 495$ million less being spent in obesity-related direct healthcare costs over twenty years.

Discussion: These findings have significant implications for policy, highlighting the need for effective strategies to prevent this avoidable health and economic burden.

Citation: Keaver L, Webber L, Dee A, Shiely F, Marsh T, et al. (2013) Application of the UK Foresight Obesity Model in Ireland: The Health and Economic Consequences of Projected Obesity Trends in Ireland. PLOS ONE 8(11): e79827. doi:10.1371/journal.pone.0079827

Editor: Josep Bassaganya-Riera, Virginia Tech, United States of America

Received June 7, 2013; Accepted October 3, 2013; Published November 13, 2013

Copyright: (c) 2013 keaver et al. This is an open-access article distributed under the terms of the Creative Commons Attribution License, which permits unrestricted use, distribution, and reproduction in any medium, provided the original author and source are credited.

Funding: This research was supported by the Irish Health Research Board funding (reference: HRC/2007/13). The funders had no role in study design, data collection and analysis, decision to publish, or preparation of the manuscript.

Competing interests: The authors have declared that no competing interested exist.

*E-mail: i.perry@ucc.ie
\end{abstract}

\section{Introduction}

Overweight and obesity have become one of the most prominent public health issues in society today, affecting countries at every stage of development. The latest estimates indicate approximately 1.46 billion people globally are overweight and 502 million of these obese [1]. The problem is rapidly penetrating into childhood with 42 million of those under the age of five estimated to be overweight globally [2].

The most recent representative data for Ireland shows that $37 \%$ of the Irish adult population are overweight and a further $24 \%$ are obese [3]. This mirrors results from the Irish National
Lifestyle Surveys (SLÁN) in 2007 [4]. In addition levels of childhood obesity in Ireland have been shown to be high when compared with our Northern European counterparts [5]. Preliminary results from a national pre-school nutrition survey indicate that $23 \%$ of those aged 2-4 years old are overweight or obese [6]. As a significant correlation exists between childhood and adolescent BMI and adult overweight and obesity, these current childhood obesity rates have the potential to contribute hugely to the health and economic burden of obesity in Ireland in the future $[7,8,9]$.

A greater recognition of the burden of disease associated with obesity has come about in recent years [10]. This health 
burden is largely driven by increased incidence of type 2 diabetes, cardiovascular diseases and some forms of cancer [11]. Both the direct and indirect healthcare costs associated with these present a significant financial burden to both public health expenditures and to the state [12]. A particularly detailed recent study in Ireland has estimated total costs attributable to obesity at 1.13 billion euro [13]. Of this $€ 399$ million were direct and $€ 729$ million were indirect costs. Direct costs refer to inpatient and day case costs, out-patient costs, GP costs and drug costs. Indirect costs are more difficult to collate and in this instance referred to productivity losses associated with work absenteeism and premature mortality. Social, psychological and emotional costs were omitted from indirect cost calculations due to a lack of national data on the economic cost of these variables.

Given the scale of the obesity epidemic there is interest nationally in determining the extent and future consequences of this issue. The UK foresight obesity model [14] has previously been applied in over 70 countries worldwide as well as each US state. Applying this model to the Irish population will provide policymakers with an idea of the potential scale of the obesity epidemic should it continue unabated, its consequences for the Irish health system, as well as the potential effect that particular policies may have if implemented. This will help guide resource allocation, population health planning and the development of effective obesity prevention and health promotion programmes to curb obesity levels within the country.

\section{Methods}

\section{Data sources}

The data sources on which the model's input parameters are based can be seen in Table 1. BMI data for Ireland was collected by conducting a search of the literature using Pubmed and Google scholar and through discussion with academic departments and other relevant national stakeholders. Databases were included if BMI data was nationally representative, presented by age and sex and categorised by WHO cut-offs for normal weight $\left(<25 \mathrm{~kg} / \mathrm{m}^{2}\right)$, pre-obesity $\left(25-29.99 \mathrm{~kg} / \mathrm{m}^{2}\right)$, and obesity $\left(\geq 30 \mathrm{~kg} / \mathrm{m}^{2}\right)$. Measured data was preferred however, due to lack of availability, some sources of self-reported data were included. Outliers were removed where data fell outside of $95 \%$ confidence limits.

A review of epidemiological studies was undertaken to find incidence, prevalence, and annual healthcare costs for each obesity-related disease: type 2 diabetes, coronary heart disease, stroke, knee osteoarthritis, hypertension and obesityrelated cancers (breast, colorectal, oesophageal, endometrial, liver, kidney and pancreas) by age and gender. The relative comorbidity risks related to being overweight or obese were obtained for each of these diseases from the International Association for the Study of Obesity [15]. Mortality and survival data were also collected for fatal diseases: CHD, stroke, cancers.

Incidence or prevalence data were not available for hypertension so UK prevalence data were used as a proxy.
Table 1. Sources of data inputs for Ireland.

\begin{tabular}{|c|c|}
\hline Category & Source of data \\
\hline \multicolumn{2}{|l|}{ Population characteristics } \\
\hline & National Adult Nutrition Survey (2011) [21] \\
\hline & SLAN (2007 [22], 2002 [23], 1998 [24]) \\
\hline \multirow{3}{*}{ BMI distribution } & North South Ireland Food Consumption Survey (2001) \\
\hline & [25] \\
\hline & The Irish Longitudinal study on Aging (2011) [26] \\
\hline Population size & Central Statistics Office (2010) [27] \\
\hline \multicolumn{2}{|l|}{ Incidence/Prevalence } \\
\hline $\mathrm{CHD}$ & Coronary Heart Attack Ireland Register (2006) [28] \\
\hline Stroke & North Dublin Population Stroke Study (2007) [29] \\
\hline Cancer & National Cancer Registry (2012) [30] \\
\hline Hypertension & Health Survey for England (2010) [31] \\
\hline Type II diabetes & Balanda et al., (2012) [32] \\
\hline Knee Osteoarthritis & Institute of Public Health (2012) [33] \\
\hline \multicolumn{2}{|l|}{ Survival } \\
\hline CHD & $\begin{array}{l}\text { European Cardiovascular Disease Statistics (2012) } \\
\text { [34] }\end{array}$ \\
\hline Stroke & Wolfe et al., (2011) [35] \\
\hline Cancers & National Cancer Registry (2010) [30] \\
\hline $\begin{array}{l}\text { Relative risks of obesity } \\
\text { on disease risks }\end{array}$ & $\begin{array}{l}\text { International Association for the Study of Obesity } \\
(2010)[36]\end{array}$ \\
\hline \multicolumn{2}{|l|}{ Disease-specific mortality } \\
\hline Coronary heart disease & Central Statistics Office (2010) [27] \\
\hline Stroke & Central Statistics Office (2010) [27] \\
\hline Cancer & National Cancer Registry (2009) [30] \\
\hline \multicolumn{2}{|l|}{ Healthcare costs } \\
\hline Direct & Health Atlas Ireland, HSE (2009) [37] \\
\hline
\end{tabular}

Survival data were not available for $\mathrm{CHD}$ or stroke so again the UK was used as a proxy to estimate survival in Ireland. These figures were adjusted for Irish population data [16].

Hypertension, Type 2 diabetes and knee osteoarthritis prevalence were converted to incidence using WHO Dismod equations [17].

\section{Statistical analysis}

A two-part modelling process was used to project the future obesity-related disease burden in Ireland. The first module fits multivariate, categorical regression models, to past and current cross-sectional BMI data, to project obesity rates to 2030 by sex. Age was included as a covariate and the predicted proportions of population in each BMI category was constrained to always total $100 \%$.

Using the BMI levels predicted in module one, and assuming that an individual's BMI status in the same-age cohort is consistent over time, module two simulates the BMI trajectory of the Irish population as it ages. A BMI value is probabilistically and stochastically assigned as a function of age, sex and calendar year. This results in a longitudinal growth model of the Irish population. The data collected on incidence and prevalence of disease, mortality and survival enabled the consequences of these BMI trends to be 


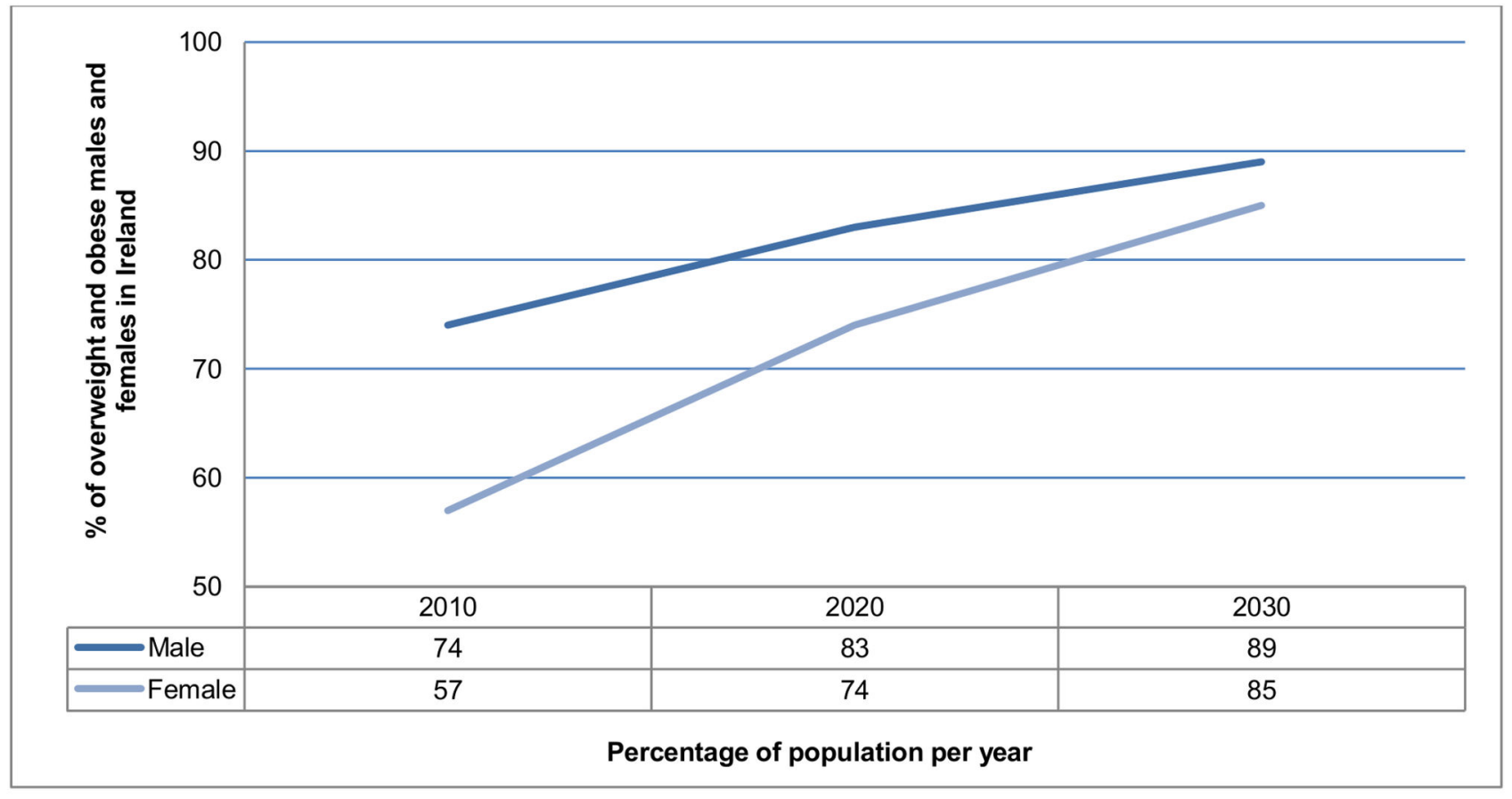

Figure 1. Projected prevalence of overweight and obesity in the Irish population. This figure shows the percentage prevalence of overweight and obesity for males and females in Ireland in 2010 and projected prevalence for overweight and obesity for males and females for 2020 and 2030.

doi: 10.1371/journal.pone.0079827.g001

determined e.g. the modelling of each individual's chance of contracting, surviving or dying from these set of conditions. The subsequent healthcare costs associated with these trends could then be determined. The software used in this program was written in $\mathrm{C}++$. Five million Monte Carlo simulation runs were performed.

The micro-simulation also modelled the effects of constraints on future BMI growth. By anticipating the outcome of interventions on BMI prevalence and its effects by age, year and sex, it was possible to explore how levels of obesityrelated chronic disease, mortality, and healthcare costs would alter following such interventions. Three different trend scenarios were estimated: scenario 0: obesity trends continue unabated; scenario 1: population BMI decreases by $1 \%$ and scenario 2: population BMI decreases by $5 \%$. Greater detail of this methodology is described in $[11,14]$ and Appendix S1.

\section{Ethical approval}

Ethical approval was granted by the Clinical Research Ethics Committee of University College Cork. The data utilised came from established databases where data encryption was already in place and subjects could not be identified. All data used remained confidential. Consent was given by the participants of the various studies at the point of data collection for this data to be stored and used for research.

\section{Results}

\section{BMI distribution}

The projected prevalence of overweight and obesity $\left(\geq 25 \mathrm{~kg} / \mathrm{m}^{2}\right)$ in males and females aged $20+$ in Ireland is illustrated in Figure 1. In both cases overweight and obesity are projected to increase by 2030 . At this point $89 \%$ of males and $85 \%$ of females are predicted to be overweight or obese, accounting for 3.5 million of the population. There will be an additional 717950 overweight or obese adults in 2030 when compared to 2010. Of these additional cases 133500 (19\%) will be over 65 years of age. While males will have higher rates of overweight or obesity $\left(\geq 25 \mathrm{~kg} / \mathrm{m}^{2}\right)$ than females they will have lower overall rates of obesity $\left(\geq 30 \mathrm{~kg} / \mathrm{m}^{2}\right) \quad(48 \%$ in males compared to $57 \%$ in females). Table $\mathrm{S} 1$ in Appendix $\mathrm{S} 2$ presents the proportion of the population in each BMI group by sex and age group projected to 2030. Figures S1 and S2 in Appendix S3 illustrate a sample of the projections with confidence limits. Childhood obesity was not projected due to a lack of representative data.

All inputs into the model represent total population figures while all outputs represent the obesity related figures.

\section{Prevalence of disease}

The obesity related prevalence of disease per 100000 population from 2010-2030 is presented in Figure 2 and illustrates how the burden of disease is projected to increase 


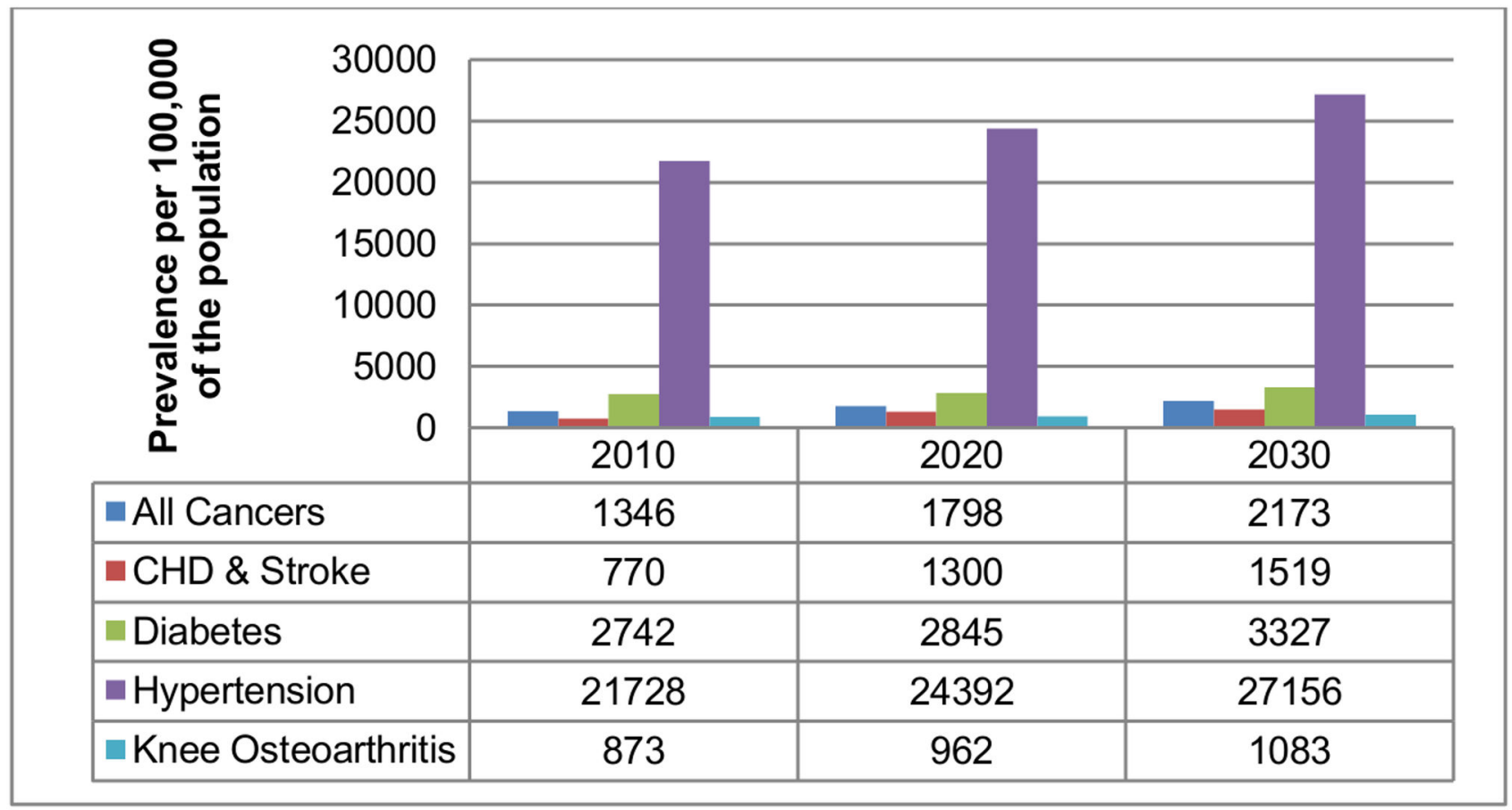

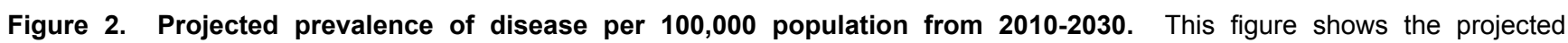
prevalence of disease per 100,000 population for 2010, 2020 and 2030 for six obesity related conditions. These six conditions are: cancer, CHD \& stroke, type 2 diabetes, hypertension and knee osteoarthritis.

doi: 10.1371/journal.pone.0079827.g002

overtime. Based on total population figures [16], there will be approximately 67899 cases of CHD \& Stroke, 97133 cases of cancer and 148717 cases of type 2 diabetes by 2030 . This represents a $97 \%, 61 \%$ and $21 \%$ increase in obesity related prevalence respectively. In addition the prevalences of nonfatal conditions such as hypertension and knee osteoarthritis are also projected to increase (affecting $27 \%$ and $1 \%$ of the total population respectively).

\section{Projected outcomes from potential interventions}

Figure 3 presents projected incident cases (obesity related) avoided per 100000 of the population from 2010 - 2030 if, when compared to no intervention (scenario 0), a $1 \%$ (scenario 1 ) and $5 \%$ (scenario 2 ) decrease in population $\mathrm{BMI}$ is achieved. The cumulative incident cases avoided range from 20/100 000 in the case of knee osteoarthritis to $824 / 100 \quad 000$ in hypertension.

A $1 \%$ reduction in $\mathrm{BMI}$ in the population has a relatively small impact on disease incidence. However, it is evident that an intervention resulting in a $5 \%$ reduction in BMI levels in the Irish population would have a significant impact on the incidence of disease, particularly CHD \& Stroke and Type 2 diabetes. Using total population figures this intervention is projected to decrease cumulative incidence by 35984 and 36788 cases respectively by 2030 . The number of incident cases avoided approximately doubles between 2020 and 2030. This intervention is also estimated to significantly reduce cumulative incidence of hypertension (by approximately 2139/100 000 or 95613 total cases within the population). A smaller though still noticeable impact is also observed on cancer incidence where 20249 fewer incident cases could be expected. Tables S2 -S5 in Appendix S4 contains results for prevalence, prevalent cases avoided through intervention, cumulative incidence and incident cases avoided through intervention.

\section{Economics}

This expansion in obesity related diseases has a significant impact on healthcare costs. If obesity trends continue unabated associated direct healthcare costs are projected to reach $€ 5.4$ billion by 2030 . The main contributors to these increased costs are CHD \& Stroke which are projected to account for $92 \%$ of obesity-related direct costs in 2030. The increase in total direct healthcare costs from 2010 to 2030 corresponds to approximately $30.3 \%$ of total healthcare spending in Ireland in 2011. Obesity-related direct healthcare costs are presented in table 2. Tables S6-S8 in Appendix S5 present the healthcare costs by year from 2010-2030.

It can be seen from table 2 that scenario 1 , where a $1 \%$ decrease in BMI is achieved across the population, is estimated to lead to direct healthcare costs that are $€ 104$ million less by 2020 and $€ 143$ million less by 2030 than scenario 0 . A $5 \%$ reduction in BMI population levels (scenario 2) has a more significant impact with $€ 394$ million and $€ 495$ 


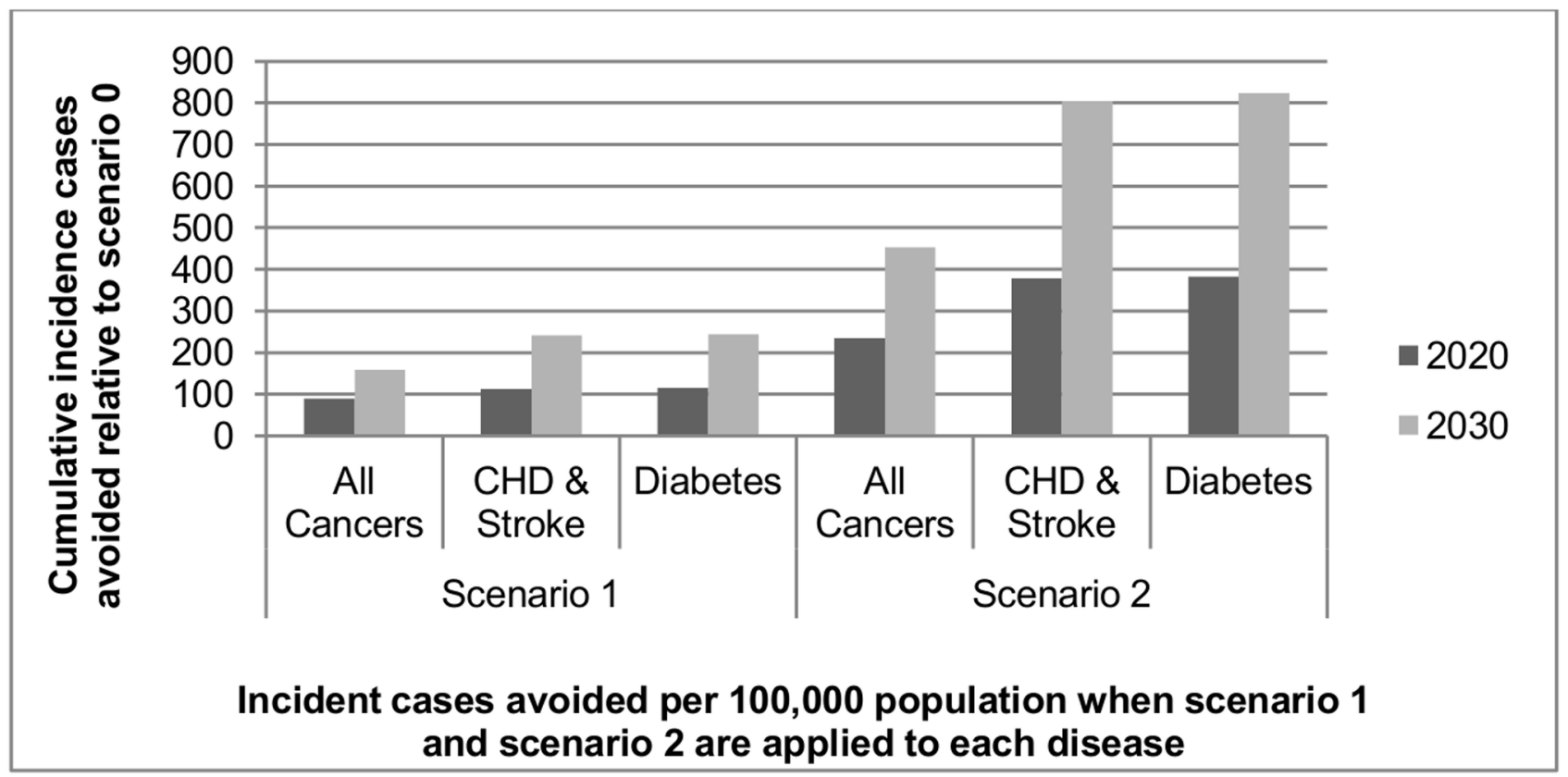

Figure 3. Cumulative incident cases avoided per 100,000 population relative to scenario 0 (when scenario 1 and scenario 2 are applied). This figure shows cumulative incident cases avoided per 100,000 population relative to scenario 0 when a $1 \%$ decrease in BMI is applied to the Irish population (scenario 1) and a $5 \%$ decrease in BMI is applied to the Irish population (scenario 2).

doi: 10.1371/journal.pone.0079827.g003

million less projected to be spent on obesity and its related comorbidities by 2020 and 2030 respectively.

\section{Discussion}

This is the first application of the UK foresight obesity model to Irish data. It is also the first to report the projected direct health care costs of six obesity related conditions, CHD \& stroke, diabetes, hypertension, cancer and knee osteoarthritis. If obesity trends continue unabated, overweight and obesity is projected to account for $89 \%$ of males and $85 \%$ of females in 2030 , leading to 288315 cumulative incident cases of cancer, 542390 of CHD \& stroke, 159490 of type 2 diabetes, 961005 of hypertension and 46533 of knee osteoarthritis. This is projected to result in obesity-related direct healthcare costs of $€ 5.4$ billion by 2030 .

A recent comprehensive study [13] of the cost of obesity in Ireland in 2009 included some estimates of indirect costs to the economy. It has been applied here to provide a crude estimate of the indirect costs of obesity which cannot be determined using the UK foresight obesity model. This was achieved by deriving the ratio of direct to indirect costs from the recent Irish study [13] and applying it to the direct healthcare costs obtained from the foresight model. We estimate that indirect costs will reach $€ 9.88$ billion in 2030. Both current and projected indirect costs are likely to be significant underestimates due to difficulty in obtaining accurate data and
Table 2. Direct healthcare costs by year and disease.

\begin{tabular}{|c|c|c|c|c|c|c|c|c|c|}
\hline \multirow[b]{2}{*}{ Year } & \multicolumn{3}{|c|}{ Scenario 0} & \multicolumn{3}{|c|}{ Scenario 1} & \multicolumn{3}{|c|}{ Scenario 2} \\
\hline & 2010 & 2020 & 2030 & 2010 & 2020 & 2030 & 2010 & 2020 & 2030 \\
\hline $\begin{array}{l}\text { Total costs }(€ \\
\text { millions) }\end{array}$ & 2547 & 4370 & 5400 & 2547 & 4270 & 5250 & 2547 & 3980 & 4900 \\
\hline CHD \& Stroke & 2265 & 4010 & 4970 & 2265 & 3920 & 4840 & 2265 & 3640 & 4510 \\
\hline Cancer & 101 & 152 & 179 & 101 & 153 & 176 & 101 & 149 & 172 \\
\hline \multicolumn{10}{|c|}{$\begin{array}{l}\text { Scenario } 0=\text { if } \mathrm{BMI} \text { trends continue unabated; Scenario } 1=\text { a } 1 \% \text { reduction in } \mathrm{BMI} \\
\text { levels relative to scenario } 0 \text { and Scenario } 2=\text { a } 5 \% \text { reduction in } \mathrm{BMI} \text { levels relative } \\
\text { to scenario } 0 \text {. } \\
\text { doi: } 10.1371 \text { journal.pone. } 0079827 . t 002\end{array}$} \\
\hline
\end{tabular}

the fact that the social, psychological and emotional effects of obesity which contribute to indirect costs are hard to quantify.

This Irish research replicates work conducted in other countries using the UK foresight obesity model. The results of this study are consistent with that found in the Russian Federation, Poland, the UK, USA and Latin America $[18,19,20,11]$, where the level of overweight and obesity is projected to increase, leading to an increased burden of disease and associated healthcare costs.

While the US has always been significantly ahead of Europe with regards obesity prevalence, modelled trends project a prevalence of $50-51 \%$ in males and $45-52 \%$ in females to 2030 in the US [11]. These figures are very similar to obesity rates projected for Ireland (48\% in males and $57 \%$ in females), 
suggesting we may catch up with the US by 2030 . It is important to note that there have been plateau's observed in obesity levels in a selection of countries worldwide, were these to occur in Ireland they would alter these projected trends beneficially.

\section{Strengths and Weaknesses}

There are many unique aspects to this model; it is modular in nature and capable of estimating the future effects of current interventions. In addition it has the ability to process and assimilate a wealth of data.

Like any research it also has its limitations. Recent increases in childhood obesity have not been incorporated into the projected adult obesity rates due to a lack of representative data. Therefore the true prevalence of obesity in 2030 and beyond is likely to be higher than that projected by the UK foresight model. In addition, the direct healthcare costs of childhood obesity have not been included in the burden calculations.

The projections can only be as accurate as the data input into the model and in many cases good quality healthcare data is difficult to locate. Drug costs for cancer were not included as recorded national data did not specify the cancer site or type. UK proxies for hypertension prevalence and CHD \& Stroke survival were used in this paper due to unavailability of Irish data in the desired format, highlighting the need for increased health surveillance in Ireland. There are too few data points available for Ireland but the estimates are still within $95 \% \mathrm{Cl}$ and reliable up to 2020 .

These projections are based on BMI trends in Ireland over the last decade and recent past trends do not always predict longer term future trends. While obesity has been increasing at a steady pace over recent decades [1], future trends can be shaped by new environments and technologies that cannot be foreseen.

\section{Conclusion}

In this research we modelled three scenarios projecting the consequences of no action and the impact of two separate interventions to reduce BMI within the population. When looking at healthcare research it is not the total cost of illness that is important but rather determining if that cost is avoidable. In the case of obesity the related disease burden and subsequent healthcare costs are avoidable.

It is clear that a $5 \%$ reduction in overweight and obesity $\left(\geq 25 \mathrm{~kg} / \mathrm{m}^{2}\right)$ levels will have a significant cost saving effect (€495 million less being spent in obesity related direct healthcare costs over the next twenty years). Governments, health policy makers, public health personnel and the food and drinks industry will now need agreement on how best to achieve this attainable target. Ignoring this inevitable demise is not an option if we have the interests of future generations at heart.
In conclusion, this research provides evidence using a recognised forecasting model of avoidable direct health care costs for six major obesity related illnesses thereby providing all those involved in healthcare provision with a platform from which to work, as well as evidence of the likely consequence of the 'do nothing new' scenario.

\section{Supporting Information}

Appendix S1. Technical information. (DOCX)

Appendix S2. BMI proportions. Table S1, Proportion of people in each BMI group by age and sex projected to 2030 . (DOCX)

Appendix S3. Sample of the projections with confidence limits. Figure S1, BMI projections for females aged 60-69. Figure S2, BMI projections for males aged 60-69. (DOCX)

\section{Appendix S4. Prevalence and Incidence.}

Table S2, Prevalent cases in year [per 100000] for Ireland. Table S3, Prevalent cases avoided in year [per 100000] for Ireland. Table S4, Cumulative incidence cases from year 2010 [per 100000 of population in 2010] for Ireland. Table S5, Cumulative incidence cases avoided from year 2010 [per 100000 of population in 2010] for Ireland.

(DOCX)

Appendix S5. Healthcare costs by year, 2010-2030. Table S6, Scenario 0 - Obesity trends continue unabated (millions of euro). Table S7, Scenario 1- 1\% decrease in population BMI. Table S8, Scenario 2- 5\% decrease in population BMI. (DOCX)

\section{Acknowledgements}

We would like to thank the following individuals and organisations who contributed to the study: the National Cancer Registry, the wider cost of obesity group and Nadine McQuillan.

\section{Author Contributions}

Conceived and designed the experiments: IP. Performed the experiments: LK. Analyzed the data: LK IP AD LW KB. Contributed reagents/materials/analysis tools: TM LW AD. Wrote the manuscript: LK. Wrote methodology: LK LW. Provided guidance: IP FS KB. Critically reviewed the manuscript: LK LW AD FS TM KB IP. Approved the final version: LK LW AD FS TM KB IP. 


\section{References}

1. Finucane MM, Stevens GA, Cowan MJ, Danaei G, Lin JK et al. (2011) National, regional and global trends in body-mass index since 1980: systematic analysis of health examination surveys and epidemiological studies with 960 country years and 9.1 million participants. Lancet; 377(9765): 557-567. Available: http://www.thelancet.com/journals/ lancet/article/PIIS0140-6736(10)62037-5/abstract. Accessed 03/07/2012 doi:10.1016/S0140-6736(10)62037-5. PubMed: 21295846.

2. WHO (2012) Controlling the global obesity epidemic. World Health Organisation. Geneva. Available: http://www.who.int/nutrition/topics/ obesity/en/. Accessed 13/08/2012.

3. IUNA (2010) ational Adult Nutrition Survey: Food and Nutrient intakes, Physical Measurements, Physical Activity Patterns and Food Choice Motives. IUNA. Available: http://www.iuna.net/wp-content/uploads/ 2010/12/National-Adult-Nutrition-Survey-Summary-ReportMarch-2011.pdf. Accessed 22/02/2013.

4. Department of Health and Children (2008) urvey of Lifestyle, Attitudes and Nutrition in Ireland. Available: http://www.dohc.ie/publications/ slan07 report.html. Accessed 06/06/2013.

5. Layte R, McCrory C (2011) Growing up in Ireland: National Longitudinal Study of Children: Overweight and obesity among 9 years olds: Child Cohort. Report 2 Department of children and youth affairs. Government Publications, Dublin. Available: http://www.growingup.ie/fileadmin/ user_upload/documents/Second_Child_Cohort_Reports/

Growing_Up_in_Ireland_-_Overweight_and_Obesity_Among_9-YearOlds.pdf. Accessed 14/02/2013.

6. Walton J (2012) National Pre-School Nutrition Survey. Summary report on: Food and Nutrient Intakes, Physical Measurements and Barriers to Healthy Eating. IUNA. Available: http://www.iuna.net/wp-content/ uploads/2012/06/

Summary Report National PreSchool Nutrition Survey June 2012.p df. Accessed 07/07/2012.

7. Murrin CM, Kelley GE, Tremblay RE, Kelleher CC (2012) Body mass index and height over the generations: evidence from the lifeways cross-generational cohort study. BMC Public Health. Available: http:// www.biomedcentral.com/1471-2458/12/81. Accessed 05/05/2013.

8. Shrivastava A, Murrin C, Sweeney ME, Heavey P, Kelleher CC (2012) Familial intergenerational and maternal aggregation patterns in nutrient intakes in the lifeways cross-generational cohort study. Public Health Nutr Aug 13:1-11. Available: http://dx.doi.org/10.1017/ S1368980012003667. Accessed 05/05/2013

9. HSE (2008) HSE Framework for Action on Obesity 2008-2012. Health Service Executive. Available: http://www.getirelandactive.ie/content/wpcontent/uploads/2011/12/HSE-Framework-for-Action-on-Obesity.pdf. Accessed 02/07/2012

10. Kopelman P (2007) Health risks associated with overweight and obesity. Obes Rev; 8 (Suppl 1): 13-17. Available: http:// onlinelibrary.wiley.com/doi/10.1111/i.1467-789X.2007.00311.x/full. Accessed 02/01/2012. doi:10.1111/j.1467-789X.2007.00311.x. PubMed: 17316295

11. Wang YC, McPherson K, Marsh T, Gortmaker SL, Brown M (2011) Health and economic burden of the projected obesity trends in the USA and the UK. Lancet, 378: 815-825. Available: http://www.thelancet.com/ journals/lancet/article/PIIS0140-6736(11)60814-3/fulltext. Accessed the 02/01/2012 doi:10.1016/S0140-6736(11)60814-3. PubMed: 21872750.

12. Jeffords JM (2010) he overall costs of obesity. The University of Vermont. Available: http://www.uvm.edu/ vlrs/Health/Overall\%20costs $\% 20$ of\%20obesity.pdf. Accessed 02/01/2012

13. Dee A, Perry IJ, Staines A, O'Neill C, McVeigh T et al. (2012) xecutive Summary: The cost of overweight and obesity on the island of Ireland. Safefood. Available: http://www.safefood.eu/SafeFood/media/ SafeFoodLibrary/Documents/Publications/Research\%20Reports/FinalExec-Summary-The-Economic-Cost-of-Obesity.pdf Accessed $01 / 11 / 2012$

14. McPherson K, Kopelman P, Butland B, Jebb S, Thomas S et al. (2007) Tackling Obesities: Future Choices-Project Report. 2nd Edition. Government; Office for Science. Available: http://www.bis.gov.uk/ assets/foresight/docs/obesity/17.pdf. Accessed 02/01/2012

15. Lobstein T, Leach RJ (2010) Data documentation for the Dynamic Modelling for Health Impact Assessment (DYNAMO-HIA) Project. Workpackage 7: Overweight and obesity report on data collection for overweight and obesity prevalence and related relative risks. London: International Association for the Study of obesity.

16. United Nations Population Prospects (2010) Population by five year age group and sex. U.N. Dept of Economic and Social Affairs. Available: http://esa.un.org/unpd/wpp/unpp/p2k0data.asp. Accessed 08/09/2012
17. WHO (2001) National Burden of Disease Studies: A Practical Guide. Edition 2.0 World Health Organisation, Global Program on Evidence for Health Policy. WHO, Geneva. Available: http://www.who.int/healthinfo/ nationalburdenofdiseasemanual.pdf. Accessed 08/09/2012.

18. Webber L, Kilpi F, Marsh T, Rtveladze K, Brown M et al. (2012a) High Rates of Obesity and Non-Communicable Diseases Predicted across Latin America. PLOS ONE 7(8): e39589. doi:10.1371/journal.pone. 0039589. PubMed: 22912663.

19. Webber L, Kilpi F, Marsh T, Rtveladze K, McPherson K et al. (2012b) Modelling obesity trends and related diseases in Eastern Europe. Obes Rev, Vol 13 (8): 744-51. doi:10.1111/j.1467-789X.2012.00999.x. PubMed: 22568760

20. Rtveladze K, Marsh T, Webber L, Kilpi F, Goryakin Y et al. (2012) Obesity Trends in Russia. The Impact on Health and healthcare costs. Scires Vol.4, No.12A: 1471-1484. Available: https:// webmailbox202.eircom.net/service/home/ /Health RUSSIA.pdf? auth $=$ co\&loc=en GB\&id=324860\&part=3 Accessed 09/01/2013.

21. National Adult Nutrition Survey (2011) Summary Report. Irish Universities Nutrition Alliance. Available: http://www.iuna.net/wpcontent/uploads/2010/12/National-Adult-Nutrition-Survey-SummaryReport-March-2011.pdf. Accessed 31/05/2013.

22. Morgan K, McGee H, Watson D, Perry I, Barry M et al. (2008) SLÁN 2007: Survey of Lifestyle, Attitudes \& Nutrition in Ireland. Main Report. Dublin: Department of Health and Children. Available: http:// www.dohc.ie/publications/pdf/slan07 report.pdf?direct=1 Accessed 31/05/2013.

23. Kelleher C, Nic Gabhainn S, Corrigan H, Daly E, Galvin M et al. (2003) Regional Results from SLAN 2002. Department of Health and Children, Dublin. Available: http://www.dohc.ie/publications/pdf/lifestyle.pdf? direct=1 Accessed 31/05/2013.

24. Friel S, Nic Gabhainn S, Kelleher C (1998) The National Health and Lifestyle Surveys: SLAN. Department of Health and Children, Dublin. Available: $\quad$ http://www.ucd.ie/issda/static/documentation/slan/slan98p1.pdf. Accessed 02/02/2013.

25. South North Ireland Food Consumption Survey (2001) Irish Universities Nutrition Alliance: Summary Report: Food And Nutrient Intakes, Anthropometry, Attitudinal Data \& Physical Activity Patterns. Food Safety Promotion Board, Dublin. Available: http://www.iuna.net/docs/ NSIFCSummary.pdf. Accessed 03/04/2013.

26. TILDA (2011) Fifty Plus in Ireland: First results from the Irish Longitudinal Study on Aging. Trinity College Dublin. Available: http:// www.tcd.ie/tilda/assets/pdf/glossy/ Tilda Master First Findings Report.pdf. Accessed 07/09/2012

27. Central Statistics Office (2010) Population size, Coronary Heart Disease Mortality, Stroke Mortality. By personal communication.

28. Coronary Heart Attack Ireland Register (2006) Prevalence of Coronoary Heart Disease in Ireland per 100,000 population. By personal communication.

29. Kelly PJ, Crispino G, Sheehan O, Kelly L, Marnane M et al. (2012) Incidence, Event Rates, and Early Outcome of Stroke in Dublin, Ireland. The North Dublin Population Stroke Study. Stroke 43(8): 2042-2047. doi:10.1161/STROKEAHA.111.645721. PubMed: 22693134

30. National Cancer Registry (2012) National Cancer Registry of Ireland (2012). Incidence, Mortality, Treatment and Survival: Relative Survival. Available: http://www.ncri.ie/survival/ RELATIVESURVIVAL WEBPAGE.shtml. Accessed 27/06/2012.

31. Health Survey for England (2010) rend tables: Hypertension Prevalence. http://www.hscic.gov.uk/pubs/hse10trends. Accessed 20/11/2012.

32. Buckley CM, Madden J, Balanda K, Barron S, Fahy L et al. (2013) Prediabetes in adults 45 years and over in Ireland: the Survey of Lifestyle, Attitudes and Nutrition in Ireland 2007. Diabet Med 30: 1198-1203. PubMed: 23659572

33. Institute of Public Health (2012) Musculoskeletal conditions briefing: September 2012. Chronic Conditions Hub. Available: http:// chronicconditions.thehealthwell.info/sites/all/libraries/tinymce/files/ CHRONIC_CONDITIONS/MSC Briefing_04_Sept_2012.pdf. Accessed 20/11/2012.

34. Nichols M, Townsend N, Luengo-Fernandez R, Leal J, Gray A et al (2012) uropean Cardiovascular Disease Statistics 2012. European Heart Network, Brussels, European Society of Cardiology, Sophia Antipolis. http://www.ehnheart.org/cvd-statistics.html accessed 20/11/2012.

35. Wolfe CDA, Crichton SL, Heuschmann PU, McKevitt CJ, Toschke AM et al. (2011) Estimates of outcomes up to ten years after stroke: Analysis from the Prospective South London Stroke Register. PLOS 
Med; 8(5): e1001033. doi:10.1371/journal.pmed.1001033. PubMed: 21610863

36. International Association for the Study of Obesity (2010) Workpackage 7: Overweight and Obesity. Report on data collection for overweight and obesity prevalence and related relative risks Available: https:/l vzmbx14.eircom.net/service/home/ /03055 BMI_WP7- datareport 20100317.pdf?auth $=$ co\&loc $=e n \_$GB\&id $=254263 \&$ part $=2$. Accessed 20/11/2012.

37. Health Atlas Ireland (2009) Direct healthcare costs. Health Intelligence Unit, Dublin. Available: https://www.healthatlasireland.ie/. Accessed 09/01/2013. 